\title{
Design and Simulation of An Energy Management Algorithm for Extended-Range Electric Bicycles
}

\author{
D.W. Yao, G. Fan, C. Zhang, J.H. Jiang, F. Wu \\ Institute of Power Machinery \& Vehicular Engineering \\ Zhejiang University \\ China
}

\begin{abstract}
A composite energy management algorithm for extended-range electric bicycles was established on the basis of traditional constant power and tracking power control strategies. With the calculation results of driving power demand and state of charge (SOC) value of battery, the algorithm can optimize the start-stop and the specific operating point of the range extender, improving the entire fuel efficiency and keeping the right SOC level of battery. A dynamic model of extended-range electric bicycle was also built with AVL CRUISE. The driving conditions of extended-range electric bicycle with the proposed energy management algorithm were then simulated and analysed. The results show that the range extender can be reasonably started and stopped according to the current SOC level of battery, and the operating point of range extender can be always maintained in the relative higher-efficiency region once started. In addition, the SOC of battery in the simulation always changes as expected of light charging and discharging. This will protect the battery as much as possible and help to prepare for the next power grid charging.
\end{abstract}

Keywords-extended-range electric bicycle; control strategy; energy management; modelling and simulation

\section{INTRODUCTION}

The development of electric vehicles now is quite limited by some critical issues, such as the high power battery cost and short driving distance. To overcome those issues, range extenders combining engine and generator are introduced to the electric vehicles. Those special devices are always ready to charge on-board batteries at any time, thus effectively extending the driving distance.

Extended-range vehicles usually have two operating modes, including pure electric mode and extended range mode [1]. In extended range model, the range extender can operate at either constant power or tracking power model. At constant power mode, the range extender is optimally controlled to work at the most efficient point. To meet the driving power demand and balance the range extender's power output, this mode usually needs larger battery capacity and can easily shorten the battery's lifetime due to frequent charging / discharging. Tracking power mode controls the range extender running in an economic zone rather than a fixed point which helps to protect the battery but results in less optimal fuel efficiency and engine-out emissions. The combination of constant power and tracking power modes to some extent overcomes the deficiencies of each mode above.
In this paper, based on the traditional constant power and tracking power control modes, an innovative composite energy management algorithm for extended-range electric bicycles was proposed and designed. The algorithm can use the driving power demand and battery SOC to optimize the start-stop and operating point of the range extender, thus helping to improve the entire fuel efficiency and keep the right SOC level of battery. The AVL CRUISE software was adopted to construct the bicycle model containing its dynamics and the energy management algorithm. Finally, the driving conditions were simulated and analyzed to verify the effectiveness of the proposed algorithm.

\section{PRINCIPLE OF EXTENDED-RANGE ELECTRIC BICYCLES}

Extended-range electric bicycles are essentially a traditional electric bicycle, but equipped with an internal combustion engine based range extender that can supply additional power at any time. The simplified diagram of an extended-range electric bicycle is shown in Fig. 1.

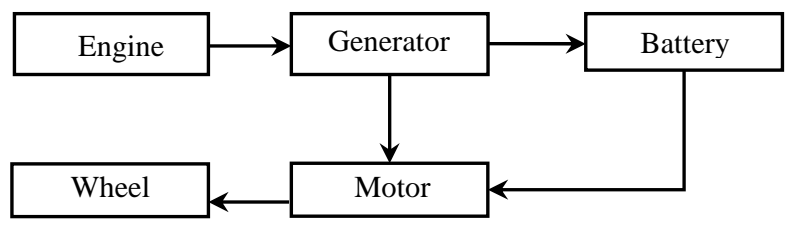

FIGURE I. SYSTEM COMPOSITION OF AN EXTENDED-RANGE ELECTRIC BICYCLE.

When the battery SOC level is high, the bicycle will operate under pure electric mode in which the motor is only powered by the battery and the range extender does not work. When the battery SOC level is low, the engine of range extender will be started to drive the generator. The generator then can drive the motor directly and recharge the battery at the same time. In such an extended range mode, the extended ranger can be optimized to continuously work at good operating points with high fuel efficiency, low level emissions and good reliability. Compared with other types of new energy driving systems, the extended range hybrid technology gets greatly improved in energy efficiency, production cost and convenience [2].

\section{ENERGY MANAGEMENT ALGORITHM DESIGN FOR EXTENDED-RANGE ELECTRIC BICYCLES}

Regarding the unique system composition of an extendedrange electric bicycle, a composite energy management 
algorithm is designed. The proposed algorithm includes current battery SOC value and driving power demand calculation as well as entire energy management. The output of algorithm can be used to control the start-stop and operating point of range extender directly.

\section{A. Current Battery SOC Value Calculation}

For battery SOC level estimation, a composite method of Ampere-time Integration (AI) and Open-circuit Voltage (OV) is adopted to calculate the current SOC value of battery. The initial battery SOC value in AI algorithm comes from the battery $\mathrm{OV}$ value that can be measured in the beginning. Thus the current battery SOC value can be calculated as:

$$
\begin{gathered}
\operatorname{SOC}(t)=\operatorname{SOC}\left(t_{0}\right)- \\
\int \eta_{d} * i_{d}(t) d t / C_{N}+\int \eta_{c} * i_{c}(t) d t / C_{N}
\end{gathered}
$$

Where, $C_{\mathrm{N}}$ is the rated capacity of battery; $i_{\mathrm{c}}$ and $i_{\mathrm{d}}$ are the instantaneous charging and discharging current; $\eta_{\mathrm{c}}$ and $\eta_{\mathrm{d}}$ are the charge and discharge coefficients; $t$ is the time; $t_{0}$ is the initial time [3].

\section{B. Driving Power Demand Calculation}

The brushless DC motor is usually used as the driving motor for electric bicycles. Therefore, the driving power demand of electric bicycles can be calculated by the following equation:

$$
P=U_{1} * I_{1}
$$

Where, $U_{1}$ and $I_{1}$ are the input voltage and current of driving motor.

\section{Energy Management Algorithm Design}

The proposed algorithm in this paper uses the driving power demand and battery SOC to optimize the start-stop and the specific operating point of the range extender. In particular, the algorithm can avoid frequent start-stop of range extender, ensure its high operating efficiency and keep the battery at a low safe SOC level to ensure following power grid charging.

A battery SOC based hysteretic gate method is used to control the start-stop status of range extender, and the control thresholds are identified by the safe battery operation avoiding over-charge / discharge. In this paper, when the battery SOC drops below $20 \%$, the range extender will be started by the internal generator; whereas the battery SOC exceeds $90 \%$ during charging, the range extender will be stopped; for the intermediate conditions, the start-stop status will remain unchanged.

Once the range extender is started, the bicycle operates under extended range mode, in which the entire energy efficiency, total driving distance and battery life are greatly affected by the control strategy of range extender. According to the battery SOC level, the algorithm in this paper tries to limit the range extender running around three most efficient power points $\left(P_{1}, P_{2}, P_{3}\right.$, and $\left.0<P_{1}<P_{2}<P_{3}<P_{\max }\right)$ along the economic operation line on range extender's engine performance map. The three power points definitely divide the engine economic operation line into four parts, including [0 $\left.P_{1}\right],\left[P_{1} P_{2}\right],\left[P_{2}, P_{3}\right]$ and $\left[P_{3} P_{\max }\right]$. The range extender will run in one area of them, depending on the current driving power demand, as shown in Fig. 2. The specific operating point of range extender in the selected area is determined by the current battery SOC value, as shown in Fig. 3.

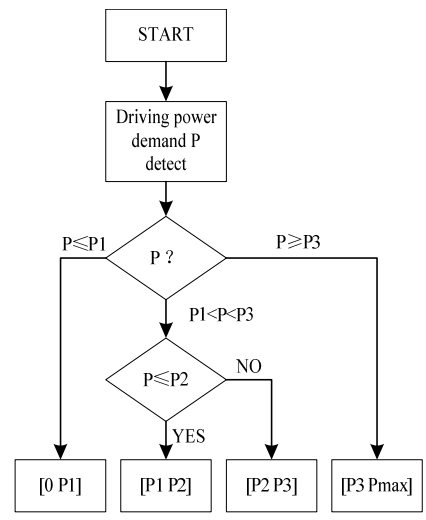

FIGURE II. OPERATION AREA CALCULATION OF RANGE EXTENDER.

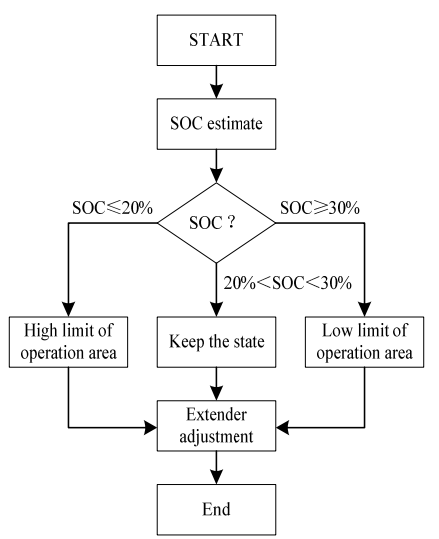

FIGURE III. OPERATING POIN CALCULATION OF RANGE EXTENDER.

In Fig. 3, 20\% is a preset low battery SOC threshold, and $30 \%$ is a high battery SOC threshold. Both of them are determined with the consideration of battery safe operation requirements. The specific operating point of range extender can be determined as follows:

(1) When the battery SOC value is higher than $30 \%$, adjust the range extender to operate at the low limit of operation area. The output power of range extender is less than the current driving power demand. Thus the battery, as an auxiliary, helps to provide power for the driving motor.

(2) When the battery SOC value drops below 20\%, adjust the range extender to operate at the high limit of operation area. The output power of range extender is greater than the current driving power demand. The surplus power can charge the battery to avoid its over discharging.

(3) When the battery SOC value is between $20 \%$ and $30 \%$, keep the state of range extender unchanged to avoid frequent adjustment of operation.

(4) If the selected operating point equals zero which means no additional power output is required, close the range extender immediately. If it equals $P_{\max }$, adjust the range 
extender to keep its output power equal the current driving power demand.

With the energy management control strategy above, the SOC value of an initially full charged battery of an extendedrange electric bicycle under constant load will undergo a typical process as shown in Fig. 4.

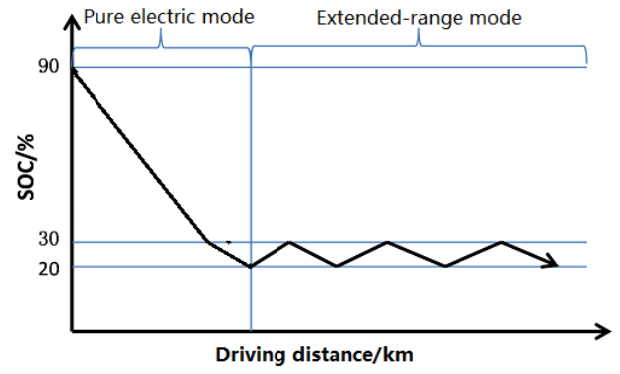

FIGURE IV. EXPECTED BATTERY SOC VALUE CHANGING OF AN EXTENDED-RANGE ELECTRIC BICYCLE.

\section{Simulation AND DisCUSSION}

\section{A. Bicycle Dynamics and Energy Management Algorithm Modeling}

The entire dynamic model of extended-range electric bicycle has been built with AVL CRUISE, as shown in Fig. 5. The modeled bicycle has a 350W driving motor, a $5 \mathrm{Ah} / 48 \mathrm{~V}$ battery, a $350 \mathrm{~W}$ range extender and a $1.6 \mathrm{~L}$ fuel tank.

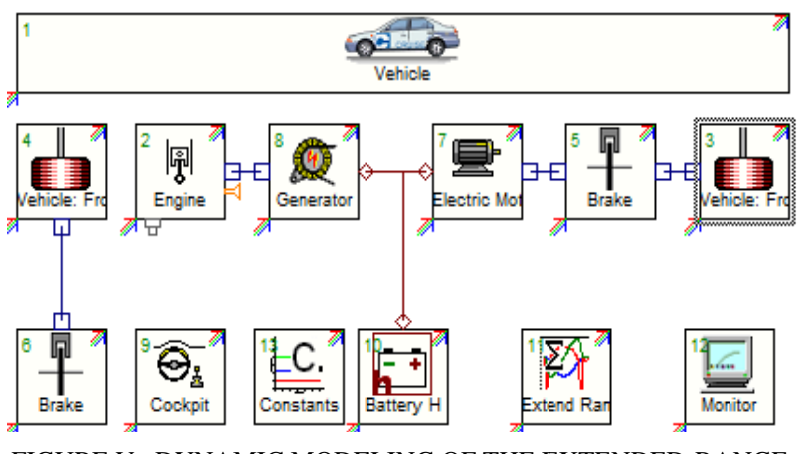

FIGURE V. DYNAMIC MODELING OF THE EXTENDED-RANGE ELECTRIC BICYCLE.

The generator of range extender in the model is electrically connected with both of driving motor and battery, thus the bicycle can operate under pure electric mode or extended range mode. The proposed composite energy management algorithm is also embedded into the entire dynamic model of extended-range bicycle by C-code module. With the cosimulation of control algorithm and bicycle dynamics, the effectiveness and feasibility of the new energy management algorithm can be verified.

\section{B. Results and Discussion}

The operating status of range extender and battery under proposed energy management algorithm is simulated and analyzed at a constant driving speed of 15km/h. Fig. 6 and Fig. 7 illustrate the simulation results.

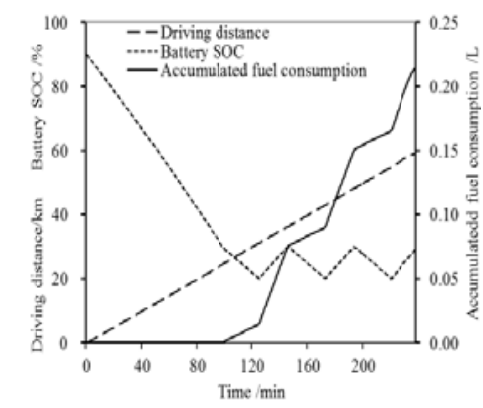

FIGURE VI. DRIVING DISTANCE, BATTERY SOC AND ACCUMULATED FUEL CONSUMPTION.

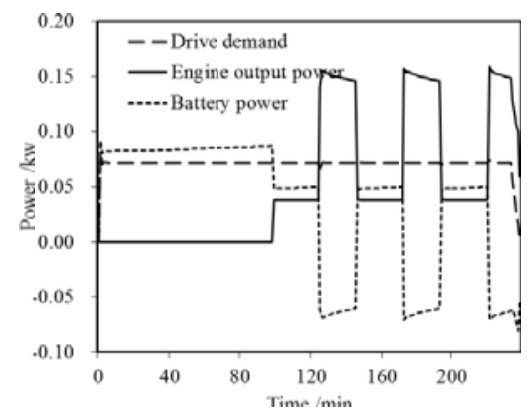

FIGURE VII. DRIVING POWER DEMAND, RANGE EXTENDER POWER AND BATTERY POWER.

Fig. 6 shows the change of driving distance, battery SOC and accumulated fuel consumption over simulation time. Due to the constant driving speed, the driving distance grows linearly. The initially full charged battery makes the bicycle start running with the pure electric model. Thus the battery SOC value decreases gradually but the accumulated fuel consumption still keeps zero. When the battery SOC value drops below $30 \%$, the range extender is started according to the strategy. As the battery SOC value is still over $20 \%$, the range extender works under lower power output, and the lack of power is supplied by the battery, thus the battery SOC value continues to decrease but at a lower speed. When the battery SOC value crosses the lowest limit of $20 \%$, the range extender is adjusted to a higher power output, and the surplus power can recharge the battery to avoid over discharging, thus the battery SOC value begins to increase. When the battery SOC value arrives at $30 \%$, the range extender again is adjusted to a lower power output and the battery discharges again. In that way, the battery can be always kept in light charging / discharging at extended range mode, helping to reduce the energy loss and prepare for the next power grid charging.

Fig. 7 shows the change of driving power demand, range extender output power and battery power over simulation time. Positive battery power means discharging, while negative one means charging. Under pure electric mode, the driving power demand is provided by the battery individually. Under extended range mode, the power output of range extender is always adjusted according to the current driving power demand and battery SOC to avoid battery over charging / discharging.

From the simulation results of Fig. 6 and Fig. 7, with the proposed energy management algorithm: the range extender 
can start and stop reasonably according to the current battery SOC level; under extended range mode, the range extender output power always changes around the driving power demand, and the battery as an auxiliary is thus kept light charging / discharging which helps to reduce the energy loss and prepare for the next power grid charging; once started, the operating point of range extender is always kept on its economic operation line, ensuring high efficiency and long entire driving distance all the time.

\section{CONCLUSIONS}

To optimize the operation of extended-range electric bicycles, a composite energy management algorithm was designed based on the traditional constant power and tracking power control strategies. The new algorithm can optimize the start-stop and the specific operating point of the range extender according to the current driving power demand and battery SOC value. An AVL CRUISE based dynamic model of extended-range electric bicycle was also built and simulated. The results show that:

(1) During the simulation, the range extender can start and stop reasonably according to the current battery SOC level, which helps to avoid the battery over charging / discharging.

(2) Under extended range mode, the range extender output power always changes around the driving power demand, thus the battery is kept in light charging / discharging all the time, which helps to extend the battery life and prepare for the next power grid charging.

(3) Once started, the operation point of range extender is always kept on its economic operation line, ensuring high efficiency and long entire driving distance all the time.

\section{ACKNOWLEDGEMENTS}

The authors greatly appreciate the financial support from the Electric Vehicle Science and Technology Innovation Team Program of Zhejiang Province in China (2011R50008-15). The authors also appreciate Xing Yue Group for their support on extended-range bicycle dynamic modeling and simulation.

\section{REFERENCE}

[1] Chen Chang-hong. Study on Control Strategy of the Extended-Range Electric Vehicle [D]. The Master Thesis of Liaoning University of Technology, 2013.

[2] E. Schacht, B. Bezaire, B. Cooley, et al. Addressing drivability in an extended range electric vehicle running an equivalent consumption minimization strategy (ECMS) [C]. SAE Technical Paper, 2011-01-091.

[3] HUA Zhou-fa, Li Jing. Summary of methods for state of charge estimation of EV power batteries [J]. Chinese Journal of Power Sources, 37(9): 1686-1689, 2013. 